\title{
Abdominal Binding Improves Neuromuscular Efficiency of the Human Diaphragm during Exercise
}

\author{
Sara J. Abdallah ${ }^{1}$, David S. Chan ${ }^{1}$, Robin Glicksman ${ }^{1}$, Cassandra T. Mendonca ${ }^{1}$, \\ Yuanming Luo $^{2}$, Jean Bourbeau ${ }^{3,4,5,6,7,8,9}$, Benjamin M. Smith ${ }^{1,3,4,5,6,7,8,9}$ and \\ Dennis Jensen ${ }^{1,3,4,5,6,7,8,9 *}$ \\ ${ }^{1}$ Clinical Exercise and Respiratory Physiology Laboratory, Department of Kinesiology and Physical Education, McGill \\ University, Montréal, QC, Canada, ${ }^{2}$ State Key Laboratory of Respiratory Disease, Guangzhou Medical University, \\ Guangzhou, China, ${ }^{3}$ Department of Medicine, Respiratory Division, McGill University, Montréal, QC, Canada, ${ }^{4}$ Respiratory \\ Epidemiology and Clinical Research Unit, Montréal Chest Institute, McGill University Health Centre, Montréal, QC, Canada, \\ ${ }^{5}$ Meakins-Christie Laboratories, Research Institute of the McGill University Health Centre, Montréal, QC, Canada, \\ ${ }^{6}$ McConnell Centre for Innovative Medicine, Research Institute of the McGill University Health Centre, Montréal, QC, Canada, \\ ${ }^{7}$ Centre for Outcomes Research and Evaluation, Research Institute of the McGill University Health Centre, Montréal, QC, \\ Canada, ${ }^{8}$ Translational Research in Respiratory Diseases Program, Research Institute of the McGill University Health Centre, \\ Montréal, QC, Canada, ${ }^{9}$ Research Centre for Physical Activity and Health, McGill University, Montréal, QC, Canada
}

\section{OPEN ACCESS}

Edited by:

Andreas Von Leupoldt, State University of Leuven, Belgium

Reviewed by: Lee M. Romer,

Brunel University London, United Kingdom

Andrew T. Lovering,

University of Oregon, United States

*Correspondence:

Dennis Jensen dennis.jensen@mcgill.ca

Specialty section: This article was submitted to Respiratory Physiology, a section of the journal Frontiers in Physiology

Received: 25 March 2017 Accepted: 11 May 2017

Published: 31 May 2017

Citation:

Abdallah SJ, Chan DS, Glicksman R, Mendonca CT, Luo Y, Bourbeau J, Smith BM and Jensen D (2017)

Abdominal Binding Improves Neuromuscular Efficiency of the Human Diaphragm during Exercise.

Front. Physiol. 8:345 doi: 10.3389/fphys.2017.00345
We tested the hypothesis that elastic binding of the abdomen (AB) would enhance neuromuscular efficiency of the human diaphragm during exercise. Twelve healthy non-obese men aged $24.8 \pm 1.7$ years (mean $\pm S E$ ) completed a symptom-limited constant-load cycle endurance exercise test at $85 \%$ of their peak incremental power output with diaphragmatic electromyography (EMGdi) and respiratory pressure measurements under two randomly assigned conditions: unbound control (CTRL) and $\mathrm{AB}$ sufficient to increase end-expiratory gastric pressure (Pga,ee) by $5-8 \mathrm{cmH}_{2} \mathrm{O}$ at rest. By design, $\mathrm{AB}$ increased $\mathrm{Pga}$,ee by $6.6 \pm 0.6 \mathrm{cmH}_{2} \mathrm{O}$ at rest. Compared to CTRL, $\mathrm{AB}$ significantly increased the transdiaphragmatic pressure swing-to-EMGdi ratio by 85-95\% during exercise, reflecting enhanced neuromuscular efficiency of the diaphragm. By contrast, $A B$ had no effect on spirometric parameters at rest, exercise endurance time or an effect on cardiac, metabolic, ventilatory, breathing pattern, dynamic operating lung volume, and perceptual responses during exercise. In conclusion, AB was associated with isolated and acute improvements in neuromuscular efficiency of the diaphragm during exercise in healthy men. The implications of our results are that $A B$ may be an effective means of enhancing neuromuscular efficiency of the diaphragm in clinical populations with diaphragmatic weakness/dysfunction.

Keywords: breathlessness, exercise, abdominal binding, neuromuscular efficiency, diaphragm

\section{INTRODUCTION}

Diaphragm muscle weakness/dysfunction is pervasive in many clinical populations, including chronic obstructive pulmonary disease (COPD), interstitial lung disease, heart failure, neuromuscular disease, critical illness and mechanical ventilation, and spinal cord injury (SCI; Baydur, 1991; Nishimura et al., 1994; Tantucci et al., 1994; Polkey et al., 1996; Baydur et al., 2001; Meyer et al., 2001; Laghi and Tobin, 2003; Brown et al., 2006; Kabitz et al., 2006, 2007; Petrof et al., 2010; West et al., 2012b). In these patient populations, diaphragm muscle weakness/dysfunction 
has been linked to increased breathlessness, impaired exercise tolerance, prolonged and difficult weaning from mechanical ventilation, and adverse health outcomes, including quality of life and death (Laghi and Tobin, 2003). It follows that nondisease specific interventions capable of increasing the pressure generating capacity of the diaphragm may have important clinical and pathophysiological implications. With the exception of inspiratory muscle training (Budweiser et al., 2006; Geddes et al., 2008; Moodie et al., 2011; Berlowitz and Tamplin, 2013; Smart et al., 2013; Martin-Valero et al., 2014) and the $\mathrm{Ca}^{2+}$ sensitizing agent, Levosimendan (van Hees et al., 2009; Doorduin et al., 2012), few generalized interventions exist to improve the force generating capacity of the human diaphragm.

Accumulating evidence from studies in health (Koulouris et al., 1989; West et al., 2012a) and SCI (Goldman et al., 1986; Hart et al., 2005; West et al., 2012a) suggest that elastic binding of the abdomen ( $\mathrm{AB}$ ) significantly increases maximal voluntary (e.g., sniff) and involuntary (e.g., twitch) pressure generating capacity of the diaphragm, presumably by reducing abdominal wall compliance, improving the operating length of the diaphragm due to its ascent to a more mechanically advantageous (cephalad) end-expiratory position, increasing intra-abdominal pressure, increasing the area of diaphragmatic apposition to the rib cage and/or increasing diaphragm-rib cage insertional forces (McCool et al., 1986; Koo et al., 2015). A series of studies by West et al. (2012a, 2014a,b) recently reported that $\mathrm{AB}$ sufficient to increase end-expiratory gastric pressure (Pga,ee) by an average of $\sim 8 \mathrm{cmH}_{2} \mathrm{O}$ at rest in athletes with cervical SCI increased transdiaphragmatic twitch pressures by $\sim 40 \%$ relative to the unbound control condition. In those studies, AB-induced improvements in diaphragmatic function were associated with concurrent improvements in static lung volumes and capacities; cardiac output at rest; the behavior of dynamic operating lung volumes during exercise; and selected measures of field-based exercise performance.

To our knowledge, only two studies have examined the impact of $\mathrm{AB}$ on exercise physiological responses in healthy adults (Vanmeenen et al., 1984; Hussain et al., 1985). Vanmeenen et al. (1984) examined the effects of decreasing vital capacity by $\sim 30 \%$ through the application of an inelastic canvas corset around the abdomen (extending from the xyphoid process to the hips, thus encompassing the lower five ribs) on exercise physiological responses in 11 healthy men. In that study, $A B$ impaired ventilatory and cardiovascular responses to exercise with attendant reductions in exercise performance, consistent with the established effects of external thoracic restriction on exercise physiological responses in healthy men (Harty et al., 1999; O’Donnell et al., 2000; Miller et al., 2002; Mendonca et al., 2014). A similar study by Hussain et al. (1985) found that applying an inelastic corset around the abdomen of five healthy men as tightly as possible while interfering minimally with ribcage movements, caused a "mild" restrictive lung deficit; significantly increased transdiaphragmatic pressure (Pdi) swings during exercise; and had no effect on exercise tolerance or an effect on ventilation $\left(\dot{V}_{\mathrm{E}}\right)$, breathing pattern and diaphragmatic electromyography (EMGdi) responses to exercise. While the study by Hussain et al. (1985) suggested that AB has the potential to enhance neuromuscular efficiency of the human diaphragm during exercise (i.e., increase ratio of Pdi-to-EMGdi), the authors did not (1) control for the degree of abdominal compression applied; (2) account for the possibility that the "mild" restrictive lung deficit imposed by $\mathrm{AB}$ may have offset the potential benefits of enhanced neuromuscular efficiency of the diaphragm on exercise tolerance; and/or (3) examine the simultaneous effect of $\mathrm{AB}$ on cardiac, metabolic, dynamic operating lung volume, and breathlessness responses to exercise.

The purpose of this study was to examine the effect of $A B$ sufficient to increase Pga,ee by $5-8 \mathrm{cmH}_{2} \mathrm{O}$ at rest on cardiac, metabolic, ventilatory, breathing pattern, dynamic operating lung volume, EMGdi, respiratory pressure, and breathlessness responses during high-intensity constant-load cycle endurance exercise testing in healthy men.

\section{MATERIALS AND METHODS Study Design}

This was a single-center, controlled, randomized, crossover study wherein eligible men participated in three testing visits over a period $\leq 2$ weeks. Visit 1 included screening of medical history, spirometry, and a symptom-limited incremental cycle exercise test to determine peak power output (PPO). Visits 2 and 3 included spirometry and a symptom-limited constantload cycle endurance exercise test at $85 \%$ of PPO with added measurements of EMGdi and respiratory pressures under two randomly assigned conditions: unbound control (CTRL) and AB. Although the conditions could not be blinded to the participants and investigators, the participants were naive to the expected outcomes of the study. Visit 1-3 were separated by $\geq 24 \mathrm{~h}$ and conducted at the same time of day $( \pm 1 \mathrm{~h})$ for each participant. Participants were instructed to avoid alcohol, caffeine, heavy meals, and strenuous exercise on each test day. The study was approved by the Institutional Review Board of the Faculty of Medicine at McGill University (A04-M42-12B) in accordance with the Declaration of Helsinski. Written informed consent was obtained from all participants prior to study initiation.

\section{Participants}

Participants included 12 non-smoking, non-obese men aged 18-40 years with normal spirometry [forced expiratory volume in $1 \mathrm{~s}\left(\mathrm{FEV}_{1}\right) \geq 80 \%$ predicted (Tan et al., 2011) and $\mathrm{FEV}_{1}$-to-forced vital capacity ratio $\left.\geq 70 \%\right]$ and no known or suspected cardiovascular, respiratory, metabolic, musculoskeletal, endocrine, and/or neuromuscular disorder(s).

\section{Abdominal Binding}

As described in detail elsewhere (West et al., 2012a), a binder made primarily of flexible neoprene (493R Universal Back Support; McDavid Inc., Woodridge, IL, USA) was individually sized and fitted with participants in the upright position and with the binder's upper edge below the costal margin so that it interfered minimally with rib-cage movement. The desired degree of abdominal compression-defined as an increase in Pga,ee of 5-8 $\mathrm{cmH}_{2} \mathrm{O}$ during steady-state breathing while seated on a chair at rest prior to exercise-was achieved by tightening 
Velcro fasteners at the front of the binder. An earlier study by West et al. (2012a) found that this level of abdominal compression optimized pulmonary function and twitch Pdi responses at rest in healthy adults and among individuals with cervical SCI.

\section{Spirometry}

Spirometry was performed using automated equipment (Vmax Encore $^{\mathrm{TM}}$, CareFusion, Yorba Linda, CA, USA) according to recommended techniques (Miller et al., 2005).

\section{Cardiopulmonary Exercise Testing}

Symptom-limited exercise tests were performed on an electronically braked cycle ergometer (VIAsprint 150P; Ergoline, Bitz, Germany) using a cardiopulmonary exercise testing system (Vmax Encore ${ }^{\mathrm{TM}}$, CareFusion). Incremental exercise tests consisted of a steady-state resting period of $\geq 6 \mathrm{~min}$, followed by $25 \mathrm{~W}$ increases in power output (starting at $25 \mathrm{~W}$ ) every 2 min: PPO was defined as the highest power output that the participant was able to sustain for $\geq 30 \mathrm{~s}$. Constant-load exercise endurance tests consisted of a steady-state resting period of $\geq 6$ min followed by a step increase in power output to $85 \%$ PPO.

Standard cardiopulmonary exercise test parameters were collected breath-by-breath (Mendonca et al., 2014; Schaeffer et al., 2014), while heart rate (HR), stroke volume (SV), and cardiac output (CO) were assessed using an impedance cardiograph (PhysioFlow ${ }^{\circledR}$; NewMeDx, Bristol, PA, USA) that provides an acceptable and non-invasive evaluation of $\mathrm{CO}$ during symptom-limited cycle exercise testing in both health and disease (Charloux et al., 2000; Richard et al., 2001). Inspiratory capacity (IC) maneuvers were performed at rest, within the last $30 \mathrm{~s}$ of every $2 \mathrm{~min}$ interval during exercise and at end-exercise (Mendonca et al., 2014; Schaeffer et al., 2014). Assuming that total lung capacity does not change during exercise with and without AB in normal males (Stubbing et al., 1980), changes in IC and inspiratory reserve volume [IRV $=\mathrm{IC}$ - tidal volume $\left.\left(\mathrm{V}_{\mathrm{T}}\right)\right]$ reflect changes in dynamic end-expiratory and end-inspiratory lung volume, respectively.

Breath-by-breath measures of the root mean square of EMGdi (EMGdi,rms) and of esophageal (Pes), gastric (Pga), and transdiaphragmatic pressure $(\mathrm{Pdi}=\mathrm{Pga}-\mathrm{Pes})$ were recorded from a gastro-esophageal electrode-balloon catheter (Guangzhou Yinghui Medical Equipment Ltd., Guangzhou, China) and analyzed using published methods (Mendonca et al., 2014; Schaeffer et al., 2014). Maximum voluntary EMGdi,rms was identified as the largest of all EMGdi,rms values obtained from IC maneuvers performed either at rest or during exercise. Tidal swings in Pes (Pes,tidal), Pga (Pga,tidal), and Pdi (Pdi,tidal) were calculated as the difference between peak tidal inspiratory and peak tidal expiratory Pes, Pga, and Pdi, respectively. The ratio of Pdi,tidal-to-EMGdi,rms was used as an index of neuromuscular efficiency of the diaphragm.

Using Borg's 0-10 category ratio scale, participants rated the intensity of their breathing overall and the intensity of their leg discomfort at rest, within the last $30 \mathrm{~s}$ of every $2 \mathrm{~min}$ interval during exercise and at end-exercise (Borg, 1982). Breathing overall (hereafter referred to as breathlessness) was defined as "the global awareness of your breathing," which is consistent with the American Thoracic Society's recommendation that the definition of breathlessness should be neutral with respect to any particular quality of breathing (Parshall et al., 2012). Leg discomfort was defined as the "difficulty associated with pedaling." Participants were asked to verbalize their main reason(s) for stopping exercise; quantify the percentage contribution of breathlessness and leg discomfort to exercise cessation; and identify qualitative phrases that best described their breathlessness at end-exercise (O'Donnell et al., 2000).

\section{Analysis of Exercise End-Points}

All physiological parameters were averaged in $30 \mathrm{~s}$ intervals at rest and during exercise. These parameters, averaged over the first $30 \mathrm{~s}$ of every $2 \mathrm{~min}$ interval during exercise, were linked with IC and symptom measurements collected during the last $30 \mathrm{~s}$ of the same minute. Three main time points were used for the evaluation of measured parameters: (1) pre-exercise rest, defined as the average of the last $60 \mathrm{~s}$ of the steady-state period after $\geq 3$ min of breathing on the mouthpiece while seated on the cycle ergometer before the start of exercise; (2) isotime, defined as the average of the first $30 \mathrm{~s}$ of the $2 \mathrm{nd}$ min of the highest equivalent 2 min interval of constant-load cycle exercise completed by a given participant with and without $\mathrm{AB}$; and (3) peak exercise, defined as the average of the last $30 \mathrm{~s}$ of loaded pedaling. Exercise endurance time (EET) was the duration of loaded pedaling.

\section{Statistical Analysis}

Two-tailed paired $t$-tests were used to examine the effects of $A B$ vs. CTRL on spirometric parameters, maximal voluntary EMGdi,rms, and the percentage contribution of breathlessness and leg discomfort to exercise cessation. A two-way repeated measures analysis of variance with Tukey's HSD post-hoc test was used to examine the effect of AB vs. CTRL on physiological and perceptual parameters measured at rest, at standardized submaximal time points during exercise (including isotime) and at peak exercise. All analyses were performed using SigmaStat ${ }^{\circledR}$, version 3.5 (Systat ${ }^{\circledR}$ Software, San Jose, CA, USA) and statistical significance was set at $p<0.05$. Data are presented as means \pm SEM.

\section{RESULTS}

\section{Participants, Abdominal Binding, and Spirometry}

Participants were healthy, young $(24.8 \pm 1.7$ years $)$, non-obese (body mass index $=23.1 \pm 0.6 \mathrm{~kg} \times \mathrm{m}^{-2}$ ) and non-smoking men with normal cardiorespiratory fitness: symptom-limited peak rate of $\mathrm{O}_{2}$ consumption $\left(\mathrm{V}_{2}\right)$ of $55.1 \pm 2.2 \mathrm{ml} \times \mathrm{kg} \times \mathrm{min}^{-1}$ or $121 \pm 6 \%$ predicted (Jones et al., 1985); and PPO of $267 \pm 18$ $\mathrm{W}$ or $109 \pm 5 \%$ predicted (Jones et al., 1985). By design, AB increased Pga,ee by $6.6 \pm 0.6 \mathrm{cmH}_{2} \mathrm{O}$ above its baseline value during the $\mathrm{AB}$ visit, but had no effect on spirometric parameters compared with CTRL (Table 1). 
TABLE 1 | Effect of abdominal binding (AB) on spirometric pulmonary function test parameters at rest in healthy men.

\begin{tabular}{lcc}
\hline Parameter & Control & AB \\
\hline FVC, L & $5.48 \pm 0.22$ & $5.35 \pm 0.25$ \\
FEV $_{1}, \mathrm{~L}(\%$ predicted $)$ & $4.41 \pm 0.19(95 \pm 3)$ & $4.27 \pm 0.21(92 \pm 4)$ \\
FEV $_{1} / \mathrm{FVC}, \%$ & $81 \pm 2$ & $80 \pm 2$ \\
PEF, L $\times \mathrm{S}^{-1}$ & $10.4 \pm 0.5$ & $9.8 \pm 0.6$ \\
$\mathrm{FEF}_{25-75 \%},{\mathrm{~L} \times \mathrm{S}^{-1}}^{-1}$ & $4.22 \pm 0.33$ & $4.04 \pm 0.34$ \\
\hline
\end{tabular}

Values are means \pm SEM. FVC, forced vital capacity; FEV 1 , forced expiratory volume in 1-sec; PEF, peak expiratory flow; $F E F_{25-75 \%}$, forced expiratory flow between 25 and $75 \%$ of the FVC maneuver.

\section{Physiological and Perceptual Responses to Exercise}

The order of experimental conditions was balanced such that 7 of the 12 participants were randomized to exercise with $\mathrm{AB}$ at Visit 2. To rule out a potentially confounding order effect on exercise performance, we compared EET between Visits 2 and Visits 3, irrespective of experimental condition and found no statistically significant difference: $9.7 \pm 1.0$ vs. $9.0 \pm 1.2 \mathrm{~min}$, respectively $(p$ $=0.290)$.

Compared to CTRL, AB had no effect on EET or an effect on cardiac, metabolic, perceptual, ventilatory, breathing pattern, and/or operating lung volume parameters at rest or during exercise (Table 2, Figures 1, 2).

The relative contributions of breathlessness (AB, $46 \pm 8 \%$ vs. CTRL, $40 \pm 7 \%$; $p=0.592)$ and leg discomfort (AB, $54 \pm$ $8 \%$ vs. CTRL, $60 \pm 7 \%$; $p=0.592)$ to exercise cessation were not different under $\mathrm{AB}$ vs. CTRL conditions. The distribution of reasons for stopping exercise were also similar between-tests: Breathlessness: $\mathrm{AB}, n=1$ vs. CTRL, $n=1$; Leg discomfort: $\mathrm{AB}, n=0$ vs. CTRL, $n=1$; Combination of breathlessness and leg discomfort: $\mathrm{AB}, n=10$ vs. CTRL, $n=9$. The majority of participants self-selected phrases alluding to a heightened sense of "work/effort of breathing" to describe their breathlessness at end-exercise under both $\mathrm{AB}$ and CTRL conditions; for example, "My breathing is heavy" (AB, $100 \%$ vs. CTRL, 92\%) and " $M y$ breathing requires more work" (AB, $92 \%$ vs. CTRL, 100\%).

\section{Diaphragmatic EMG and Respiratory Pressures}

Maximal voluntary EMGdi,rms was not significantly different under $\mathrm{AB}$ vs. CTRL conditions: $227 \pm 19$ vs. $234 \pm 25 \mu \mathrm{V}$, respectively ( $p=0.727$ ). Peak inspiratory Pes values recorded during serial IC maneuvers did not change significantly from rest $\left(\mathrm{AB},-34.2 \pm 3.4 \mathrm{cmH}_{2} \mathrm{O}\right.$; CTRL, $\left.-34.5 \pm 2.2 \mathrm{cmH}_{2} \mathrm{O}\right)$ and throughout exercise (e.g., $\mathrm{AB}$ at end-exercise, $-34.8 \pm$ $2.9 \mathrm{cmH}_{2} \mathrm{O}$; CTRL at end-exercise, $-36.1 \pm 2.6 \mathrm{cmH}_{2} \mathrm{O}$ ) both within and between conditions. Peak inspiratory Pdi values recorded during serial IC maneuvers (Pdi,IC) performed at rest and throughout exercise were significantly increased by $18.5-$ $22.2 \mathrm{cmH}_{2} \mathrm{O}$ (or 43-53\%) under $\mathrm{AB}$ vs. CTRL conditions; for example, $\mathrm{AB}, 70.3 \pm 6.0 \mathrm{cmH}_{2} \mathrm{O}$ vs. CTRL, $48.5 \pm 4.9 \mathrm{cmH}_{2} \mathrm{O}$ at rest $(p<0.001)$; and $\mathrm{AB}, 59.2 \pm 4.0 \mathrm{cmH}_{2} \mathrm{O}$ vs. CTRL, $40.2 \pm$ $2.8 \mathrm{cmH}_{2} \mathrm{O}$ at end-exercise $(p<0.001)$.

Compared with CTRL, AB had no effect on either EMGdi,rms (Figure 3A) or Pes (Figure 3C) responses during exercise (Table 2). As expected, peak tidal inspiratory Pga (Pga,inspir) and peak tidal expiratory Pga (Pga,expir) were consistency higher at rest and during exercise with vs. without $\mathrm{AB}$ (Table 2, Figure 3E). Compared with CTRL, AB increased Pdi,tidal and peak tidal inspiratory Pdi (Pdi,inspir) at rest and during exercise; for example, by $+16.5 \mathrm{cmH}_{2} \mathrm{O}$ at rest and by +28.2 $\mathrm{cmH}_{2} \mathrm{O}$ during exercise at isotime with vs. without $\mathrm{AB}$ (Table 2, Figure 3B). Furthermore, $A B$ was associated with a marked increase in the magnitude of the exercise-induced rise in Pdi,tidal and Pdi,inspir (Table 2, Figure 3B): the respective increases in Pdi,tidal and Pdi,inspir from rest to isotime during exercise were $\sim 315$ and $223 \%$ greater with vs. without AB. As illustrated in Figure 3D, Pdi,tidal and Pdi,inspir were much higher at any given EMGdi,rms during exercise with vs. without $\mathrm{AB}$, indicating enhanced neuromuscular efficiency of the diaphragm. Indeed, $\mathrm{AB}$ increased the Pdi,tidal:EMGdi,rms ratio by an average of 85-95\% at each measurement time during exercise (Table 2, Figure 3F).

\section{DISCUSSION}

The main finding of this study was that $\mathrm{AB}$ sufficient to increase intra-abdominal pressure by an average of $6.6 \mathrm{cmH}_{2} \mathrm{O}$ at rest enhanced neuromuscular efficiency of the diaphragm during exercise, but had no effect on exercise endurance nor an effect on cardiac, metabolic, ventilatory, breathing pattern, dynamic operating lung volume, and perceptual responses to exercise in healthy young men.

In keeping with the results of earlier $\mathrm{AB}$ studies in health (Hussain et al., 1985) and SCI (Hart et al., 2005; West et al., 2012a, 2014a,b), the increased Pdi,tidal, Pdi,inspir, and Pdi,IC responses observed at rest and during exercise with vs. without $\mathrm{AB}$ were mechanistically linked to increased intra-abdominal pressures (i.e., Pga,ee and Pga,expir). The increased intra-abdominal pressures associated with $\mathrm{AB}$ effectively shift the abdominal contents toward the diaphragm (cephalad), thereby increasing both insertional and appositional forces of the diaphragm on the lower rib cage (Wilson and De Troyer, 2013; Koo et al., 2015). By shifting the diaphragm cephalad, $\mathrm{AB}$ also lengthens diaphragm muscle fibers and optimizes its length-tension relationship (Koo et al., 2015). As a result, the diaphragm initiates its inspiratory contraction at a longer length, thus generating a greater pressure at any given level of muscle activation, reflecting enhanced diaphragmatic contractility (De Troyer, 1983). Abdominal binding may further enhance pressuregenerating capacity of the diaphragm by improving (reducing) abdominal compliance, thus impeding diaphragmatic descent at the costal fibers during inspiration and minimizing muscle fiber shortening, i.e., maintaining the muscle length on a more favorable region of the length-tension curve (De Troyer, 1983; Hart et al., 2005; Koo et al., 2015). Finally, by increasing intraabdominal pressures and decreasing abdominal compliance, 
TABLE 2 | Effect of abdominal binding (AB) on physiological and perceptual responses to constant-load cycle endurance exercise testing at $85 \%$ of symptom-limited peak incremental power output (equivalent to $227 \pm 17 \mathrm{~W}$ ) in healthy men.

\begin{tabular}{|c|c|c|c|c|c|c|}
\hline Parameter & \multicolumn{2}{|c|}{ REST } & \multicolumn{2}{|c|}{ ISO-TIME } & \multicolumn{2}{|c|}{ PEAK } \\
\hline Breathlessness, Borg 0-10 units & $0.2 \pm 0.2$ & $0.3 \pm 0.2$ & $6.1 \pm 0.6$ & $6.8 \pm 0.6$ & $8.1 \pm 0.7$ & $8.3 \pm 0.7$ \\
\hline Leg Discomfort, Borg 0-10 units & $0.0 \pm 0.0$ & $0.0 \pm 0.0$ & $6.9 \pm 0.7$ & $7.3 \pm 0.6$ & $8.1 \pm 0.7$ & $8.3 \pm 0.5$ \\
\hline$\dot{\mathrm{VO}}_{2}, \mathrm{ml} \times \mathrm{kg} \times \mathrm{min}^{-1}$ & $5.6 \pm 0.2$ & $5.1 \pm 0.5$ & $51.6 \pm 2.3$ & $51.5 \pm 2.5$ & $53.6 \pm 2.1$ & $52.4 \pm 2.5$ \\
\hline $\mathrm{HR}$, beats $\times \mathrm{min}^{-1}$ & $78.4 \pm 3.2$ & $76.3 \pm 3.2$ & $172.7 \pm 3.4$ & $174.1 \pm 3.3$ & $182.6 \pm 2.3$ & $178.7 \pm 2.9$ \\
\hline SV, ml & $75.6 \pm 4.3$ & $70.9 \pm 3.8$ & $117.9 \pm 6.4$ & $118.5 \pm 6.1$ & $116.6 \pm 6.5$ & $119.8 \pm 6.0$ \\
\hline$\dot{\mathrm{V}}_{E}, \mathrm{~L} \times \mathrm{min}^{-1}$ & $12.5 \pm 0.9$ & $11.2 \pm 0.9$ & $116.4 \pm 7.3$ & $120.7 \pm 7.7$ & $133.4 \pm 8.0$ & $130.6 \pm 8.6$ \\
\hline $\mathrm{V}_{T}, \mathrm{~L}$ & $0.90 \pm 0.09$ & $0.74 \pm 0.06$ & $2.96 \pm 0.17$ & $2.90 \pm 0.21$ & $2.72 \pm 0.17$ & $2.73 \pm 0.19$ \\
\hline$f_{R}$, breaths $\times \min ^{-1}$ & $15.2 \pm 1.1$ & $15.7 \pm 0.8$ & $39.9 \pm 2.0$ & $42.8 \pm 2.4$ & $50.4 \pm 3.6$ & $49.8 \pm 4.0$ \\
\hline EMGdi\%max & $10.4 \pm 1.1$ & $13.1 \pm 2.1$ & $56.0 \pm 2.8$ & $53.0 \pm 2.9$ & $61.9 \pm 5.2$ & $53.3 \pm 3.4$ \\
\hline End-expiratory Pes, $\mathrm{cmH}_{2} \mathrm{O}$ & $-7.3 \pm 0.7$ & $-5.0 \pm 0.7$ & $-5.4 \pm 1.1$ & $-4.3 \pm 1.2$ & $-6.0 \pm 1.1$ & $-5.3 \pm 0.9$ \\
\hline Pes,tidal, $\mathrm{cmH}_{2} \mathrm{O}$ & $6.1 \pm 0.9$ & $4.8 \pm 0.6$ & $31.6 \pm 2.9$ & $31.2 \pm 2.6$ & $35.0 \pm 3.0$ & $34.5 \pm 2.8$ \\
\hline Peak inspiratory Pes, $\mathrm{cmH}_{2} \mathrm{O}$ & $-11.7 \pm 1.8$ & $-8.4 \pm 0.8$ & $-23.6 \pm 1.9$ & $-21.5 \pm 1.7$ & $-24.3 \pm 1.9$ & $-22.0 \pm 1.9$ \\
\hline Peak expiratory Pes, $\mathrm{cmH}_{2} \mathrm{O}$ & $-5.6 \pm 0.7$ & $-3.5 \pm 0.8$ & $8.1 \pm 2.3$ & $9.8 \pm 1.5$ & $10.8 \pm 2.2$ & $12.5 \pm 1.7$ \\
\hline End-expiratory $\mathrm{Pga}, \mathrm{cmH}_{2} \mathrm{O}$ & $7.7 \pm 1.2$ & $12.3 \pm 1.2^{\star}$ & $14.3 \pm 1.4$ & $17.8 \pm 0.9$ & $14.4 \pm 1.3$ & $19.1 \pm 1.1^{\star}$ \\
\hline Pga,tidal, $\mathrm{cmH}_{2} \mathrm{O}$ & $5.2 \pm 0.5$ & $9.0 \pm 0.8$ & $17.3 \pm 1.7$ & $18.0 \pm 1.3$ & $19.2 \pm 1.6$ & $17.1 \pm 1.1$ \\
\hline Peak inspiratory Pga, $\mathrm{cmH}_{2} \mathrm{O}$ & $6.5 \pm 1.3$ & $11.7 \pm 1.2^{\top}$ & $4.3 \pm 1.2$ & $14.0 \pm 1.0^{\dagger}$ & $4.3 \pm 1.1$ & $14.8 \pm 0.9^{\dagger}$ \\
\hline Peak expiratory Pga, $\mathrm{cmH}_{2} \mathrm{O}$ & $11.7 \pm 1.6$ & $20.7 \pm 1.5^{\star}$ & $21.6 \pm 1.9$ & $32.0 \pm 1.7^{\dagger}$ & $23.5 \pm 1.9$ & $31.9 \pm 1.6^{*}$ \\
\hline End-expiratory $\mathrm{Pdi}, \mathrm{cmH}_{2} \mathrm{O}$ & $15.1 \pm 0.9$ & $17.3 \pm 0.9$ & $19.6 \pm 1.3$ & $22.0 \pm 1.2$ & $20.4 \pm 1.2$ & $24.5 \pm 1.3$ \\
\hline
\end{tabular}

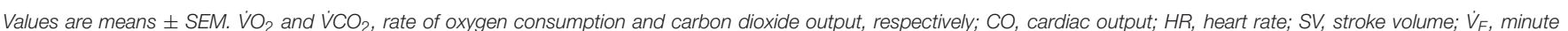

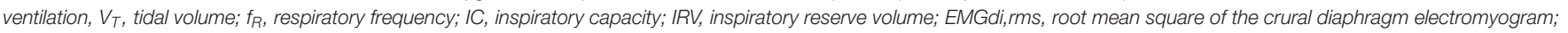

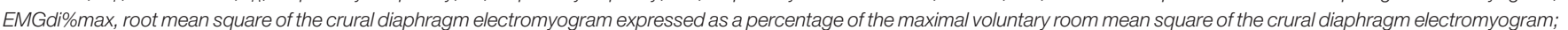

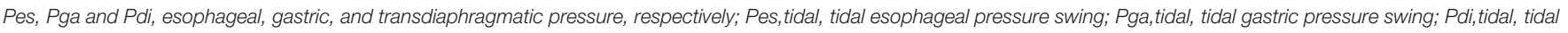

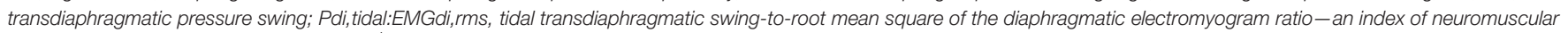
efficiency of the diaphragm. ${ }^{*} p<0.05$ and ${ }^{\dagger} p \leq 0.01$ vs. Control.

$\mathrm{AB}$ may increase the inflationary action of the diaphragm on the lower rib cage by increasing the zone of apposition and improving the diaphragm's ability to lift and expand the lower rib cage (De Troyer, 1983; Koo et al., 2015). The combination of these mechanically advantageous changes to the shape and configuration of the diaphragm are most likely responsible for the 85-95\% increase in neuromuscular efficiency of the diaphragm observed during exercise with vs. without $\mathrm{AB}$.

Although $\mathrm{AB}$ increased diaphragmatic contractility/pressuregenerating capacity, it had no demonstrable effect on EMGdi,rms, Pes, $\dot{V}_{E}$, breathing pattern, and dynamic operating lung volume responses to exercise. These findings are similar to those of earlier AB studies by Hussain et al. (1985) in health and by West et al. (2014b) in SCI, and presumably reflect the fact that
$\mathrm{AB}$ had no untoward effect on expiratory flow generation during exercise (as evidenced by relative preservation of the relationship between exercise-induced increases in peak tidal expiratory Pes and peak expiratory flow) or an effect on exercise-induced increases the rate of $\mathrm{CO}_{2}$ production, which is the proximate source of increased ventilatory requirements during exercise. It could be argued that the increased intra-abdominal pressures associated with $\mathrm{AB}$ may have hindered descent of the diaphragm into the abdomen at rest and particularly during exercise when ventilatory requirements were $\sim 13$-fold higher than at rest. If this was true, then maximal voluntary EMGdi,rms as well as the magnitude of exercise-induced increases in EMGdi,rms should have been consistently higher under $\mathrm{AB}$ vs. CTRL conditions. However, this is not what we observed in our study nor what 
A

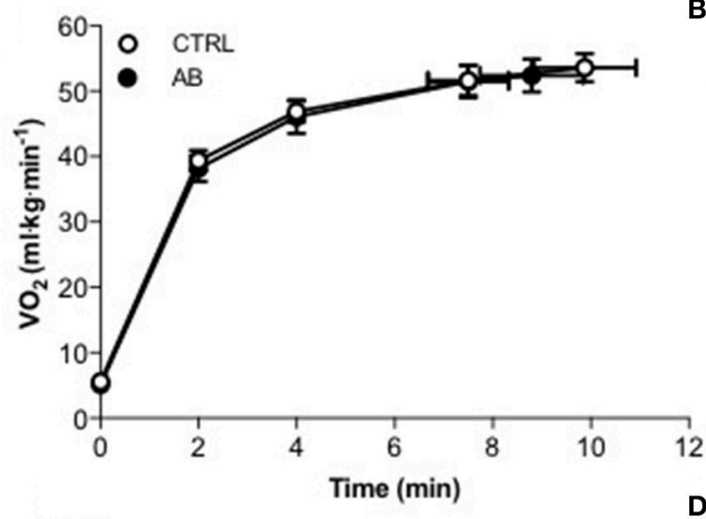

C

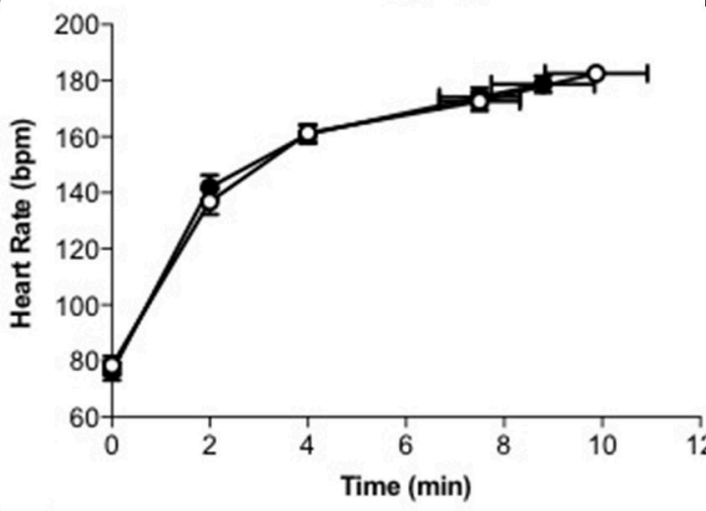

E

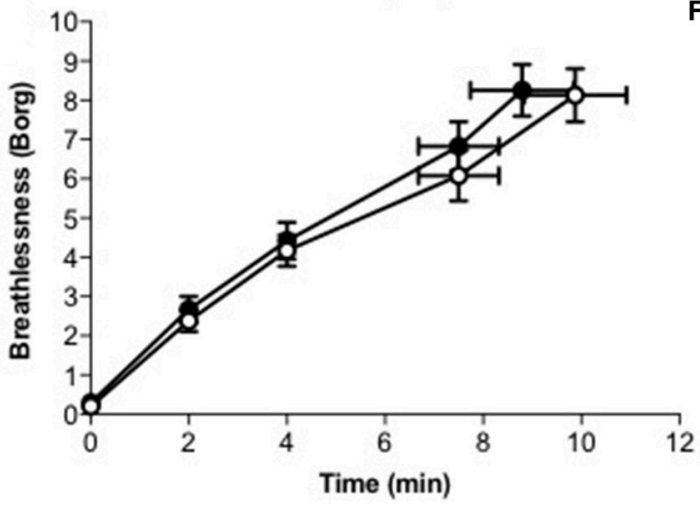

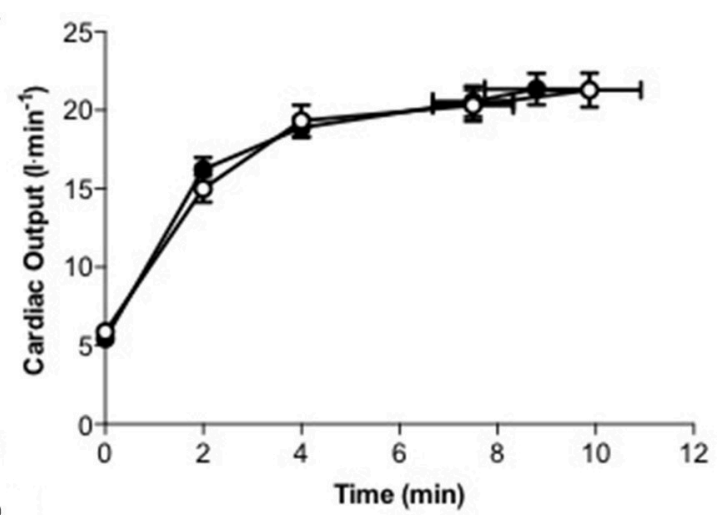

D

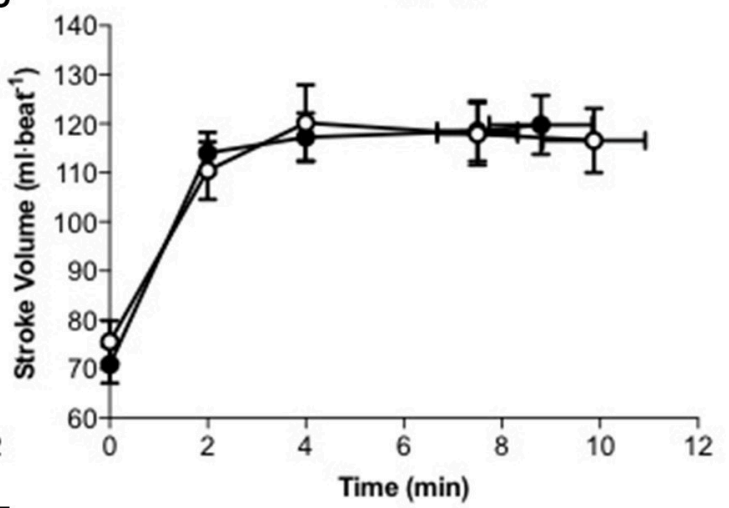

$\mathbf{F}$

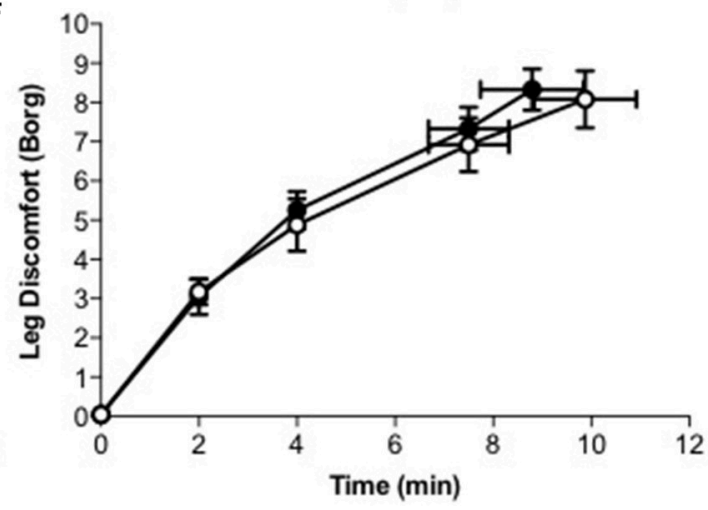

FIGURE 1 | Effect of abdominal binding (AB) vs. control (CTRL) on (A) the rate of oxygen consumption $\left(\dot{\mathrm{V}} \mathrm{O}_{2}\right)$, (B) cardiac output (C) heart rate, (D) stroke volume, (E) breathlessness, and (F) leg discomfort responses during constant-load cycle endurance exercise testing at $85 \%$ of peak incremental power output in healthy men. Values are means \pm SEM.

Hussain et al. (1985) reported in their AB study of five healthy men.

In the setting of a relatively preserved EMGdi,rms, $\dot{V}_{E}$, breathing pattern and dynamic operating lung volume response to exercise with vs. without $A B$, we speculate that the disparate effect of $\mathrm{AB}$ on Pdi and Pes responses to exercise reflected "offloading" of the inspiratory action(s) of the rib cage muscles. In other words, by increasing Pdi,inspir and thus Pdi,tidal responses to exercise, $\mathrm{AB}$ effectively decreased the rib cage muscles' relative contribution to any given level of negative intrathoracic pressure development throughout inspiration during exercise.
Additional research with simultaneous measures of accessory inspiratory muscle EMG activity is needed to confirm this postulate.

In the absence of changes in EMGdi,rms, $\dot{\mathrm{V}}_{\mathrm{E}}$, breathing pattern, expiratory flow generation, and dynamic operating lung volume responses to exercise, isolated and acute improvements in neuromuscular efficiency of the diaphragm during exercise with vs. without $A B$ had no effect on exercise endurance and/or exertional breathlessness. These findings support the view that, in healthy young adults: (1) respiratory mechanical/muscular factors do not likely contribute to the limits of exercise tolerance; 

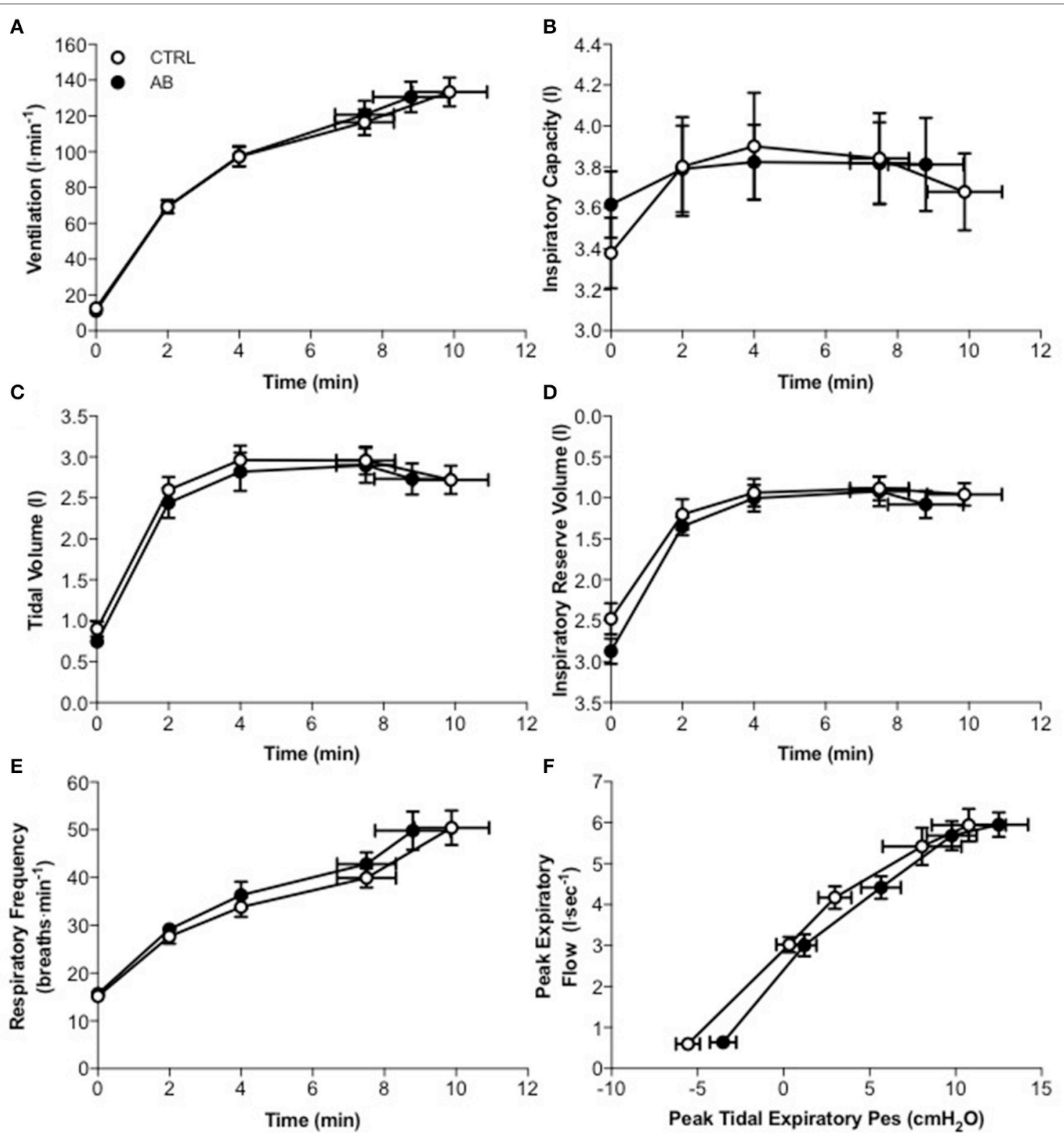

FIGURE 2 | Effect of abdominal binding (AB) vs. control (CTRL) on (A) ventilation, (B) inspiratory capacity, (C) tidal volume, (D) inspiratory reserve volume, (E) respiratory frequency, and (F) peak expiratory flow vs. peak tidal expiratory esophageal pressure (Pes) responses during constant-load cycle endurance exercise testing at $85 \%$ of peak incremental power output in healthy men. Values are means $\pm \mathrm{SEM}$.

and (2) progressive neuromuscular uncoupling of the diaphragm is not likely a proximate source of exertional breathlessness. Nevertheless, the results of our study provide a physiological rationale for future examination of $A B$ as a potentially effective non-pharmacological means of improving exercise tolerance in pathophysiological disease states where neuromuscular uncoupling of the diaphragm has been mechanistically linked to a heightened perception of exertional breathlessness, most notably in patients with COPD (Laghi et al., 1998). Interestingly, a case report by Celli et al. (1985) found that $\mathrm{AB}$ sufficient to increase Pga,ee from 4 to $12 \mathrm{cmH}_{2} \mathrm{O}$ was associated with objective and potentially clinically meaningful improvements in diaphragmatic function, exercise tolerance, and breathlessness in a symptomatic patient with severe COPD and a large midline hernia of the anterior abdominal wall.

The collective results of studies by Vivier et al. (2006), Aliverti et al. (2009, 2010), and Uva et al. (2015) suggest that $\mathrm{AB}$, by increasing intra-abdominal pressure and/or the abdominal circulatory pump action of the diaphragm and abdominal muscles, has the potential to improve cardiac function at rest and during exercise by increasing central venous return from the splanchnic venous circulation. In our 

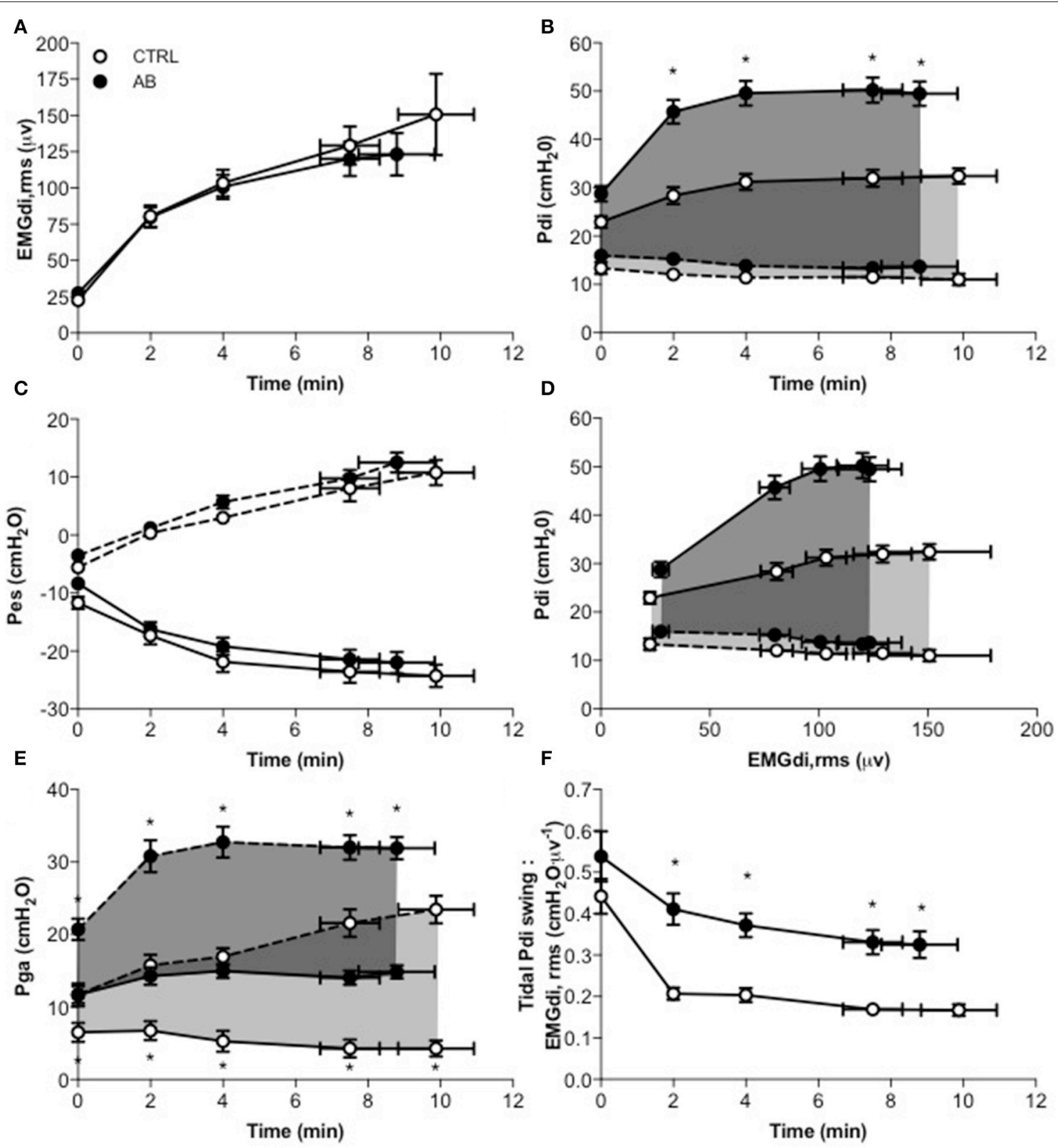

FIGURE 3 | Effect of abdominal binding (AB) vs. control (CTRL) on (A) root mean square of the crural diaphragm electromyogram (EMGdi,rms), (B) transdiaphragmatic pressure (Pdi), (C) esophageal pressure (Pes), (D) Pdi vs. EMGdi,rms, (E) gastric pressure (Pga), and (F) tidal Pdi swing-to-EMGdi,rms ratio responses during constant-load cycle endurance exercise testing at $85 \%$ of peak incremental power output in healthy men. Values are means \pm SEM. ${ }^{*} p<0.05$ vs. CTRL. Dashed lines denote expiratory Pdi, Pes and Pga.

study, however, $\mathrm{AB}$ had no demonstrable effect on impedance cardiograph-derived estimates of $\mathrm{CO}$ and $\mathrm{SV}$ at rest and during exercise, which is in agreement with West et al. (2012a) who reported no effect of $\mathrm{AB}$ on echocardiography-derived measures of cardiac function at rest (e.g., CO, SV, enddiastolic volume, end-systolic volume, ejection fraction) in eight healthy adults. We speculate that $\mathrm{AB}$-induced increases in intra-abdominal pressure and/or the abdominal circulatory pump action of the diaphragm and abdominal muscles were of insufficient magnitude(s) to shift large enough quantities of blood from the splanchnic to central venous circulation to enhance cardiac function at rest and during exercise in our participants.

In summary, the increased intra-abdominal pressures associated with $\mathrm{AB}$ enhanced neuromuscular efficiency of the diaphragm by $85-95 \%$ during high-intensity constant-load cycle endurance exercise testing in healthy men. Additional research is recommended to examine potential benefits of 
$\mathrm{AB}$ on exertional symptoms in clinical populations where diaphragmatic weakness/dysfunction has been implicated as a source of physical activity-related breathlessness and exercise intolerance.

\section{AUTHOR CONTRIBUTIONS}

SA, DC, RG, and DJ contributed to the conception of the study as well as to data collection, analysis, and interpretation. CM contributed to data collection and analysis. SA and DJ wrote the manuscript, with critical input from all other authors. All authors read and approved the final version of the manuscript.

\section{FUNDING}

This study was financially supported by a Discovery Grant from the Natural Sciences and Engineering Research Council

\section{REFERENCES}

Aliverti, A., Bovio, D., Fullin, I., Dellaca, R. L., Lo Mauro, A., Pedotti, A., et al. (2009). The abdominal circulatory pump. PLoS ONE 4:e5550. doi: 10.1371/journal.pone.0005550

Aliverti, A., Uva, B., Laviola, M., Bovio, D., Lo Mauro, A., Tarperi, C., et al. (2010). Concomitant ventilatory and circulatory functions of the diaphragm and abdominal muscles. J. Appl. Physiol. 109, 1432-1440. doi: 10.1152/japplphysiol.00576.2010

Baydur, A. (1991). Respiratory muscle strength and control of ventilation in patients with neuromuscular disease. Chest 99, 330-338. doi: 10.1378/chest.99.2.330

Baydur, A., Alsalek, M., Louie, S. G., and Sharma, O. P. (2001). Respiratory muscle strength, lung function, and dyspnea in patients with sarcoidosis. Chest 120, 102-108. doi: 10.1378/chest.120.1.102

Berlowitz, D. J., and Tamplin, J. (2013). Respiratory muscle training for cervical spinal cord injury. Cochrane Database Syst. Rev. CD008507. doi: 10.1002/14651858.CD008507.pub2

Borg, G. A. (1982). Psychophysical bases of perceived exertion. Med. Sci. Sports Exerc. 14, 377-381. doi: 10.1249/00005768-198205000-00012

Brown, R., DiMarco, A. F., Hoit, J. D., and Garshick, E. (2006). Respiratory dysfunction and management in spinal cord injury. Respir. Care 51, 853-868. discussion: 869-870.

Budweiser, S., Moertl, M., Jorres, R. A., Windisch, W., Heinemann, F., and Pfeifer, M. (2006). Respiratory muscle training in restrictive thoracic disease: a randomized controlled trial. Arch. Phys. Med. Rehabil. 87, 1559-1565. doi: 10.1016/j.apmr.2006.08.340

Celli, B. R., Rassulo, J., Berman, J. S., and Make, B. (1985). Respiratory consequences of abdominal hernia in a patient with severe chronic obstructive pulmonary disease. Am. Rev. Respir. Dis. 131, 178-180.

Charloux, A., Lonsdorfer-Wolf, E., Richard, R., Lampert, E., Oswald-Mammosser, M., Mettauer, B., et al. (2000). A new impedance cardiograph device for the non-invasive evaluation of cardiac output at rest and during exercise: comparison with the "direct" Fick method. Eur. J. Appl. Physiol. 82, 313-320. doi: $10.1007 / \mathrm{s} 004210000226$

De Troyer, A. (1983). Mechanical role of the abdominal muscles in relation to posture. Respir. Physiol. 53, 341-353. doi: 10.1016/0034-5687(83)90124-X

Doorduin, J., Sinderby, C. A., Beck, J., Stegeman, D. F., van Hees, H. W., van der Hoeven, J. G., et al. (2012). The calcium sensitizer levosimendan improves human diaphragm function. Am. J. Respir. Crit. Care Med. 185, 90-95. doi: 10.1164/rccm.201107-1268OC

Geddes, E. L., O’Brien, K., Reid, W. D., Brooks, D., and Crowe, J. (2008). Inspiratory muscle training in adults with chronic obstructive pulmonary disease: an update of a systematic review. Respir. Med. 102, 1715-1729. doi: 10.1016/j.rmed.2008.07.005 of Canada (RGPIN 402598-2011) to DJ. SA was funded by a Ph.D. Recruitment Award (McGill University), a Ruth Hoyt Cameron Fellowship, a Max Bell Fellowship, and a Frederik Banting and Charles Best Graduate ScholarshipDoctoral Award (CGS-D) from the Canadian Institutes of Health Research (201410GSD-347900-243684). DC was supported by an Undergraduate Summer Research Studentship Award from the Natural Sciences and Engineering Research Council of Canada. RG was supported by an Adriano Tassone Undergraduate Summer Research Studentship Award. CM was supported by a Canadian Institutes of Health Research-Québec Respiratory Health Training Program Award. BS was supported by a Chercheurs-Boursiers Cliniciens Junior 1 salary award from the Fonds de recherche du Québec-Santé. DJ was supported by a Chercheurs-Boursiers Junior 1 salary award from the Fonds de Recherche du Québec-Santé, a William Dawson Research Scholar Award from McGill University, and a Canada Research Chair in Clinical Exercise \& Respiratory Physiology.

Goldman, J. M., Rose, L. S., Williams, S. J., Silver, J. R., and Denison, D. M. (1986). Effect of abdominal binders on breathing in tetraplegic patients. Thorax 41, 940-945. doi: 10.1136/thx.41.12.940

Hart, N., Laffont, I., de la Sota, A. P., Lejaille, M., Macadou, G., Polkey, M. I., et al. (2005). Respiratory effects of combined truncal and abdominal support in patients with spinal cord injury. Arch. Phys. Med. Rehabil. 86, 1447-1451. doi: 10.1016/j.apmr.2004.12.025

Harty, H. R., Corfield, D. R., Schwartzstein, R. M., and Adams, L. (1999). External thoracic restriction, respiratory sensation, and ventilation during exercise in men. J. Appl. Physiol. 86, 1142-1150.

Hussain, S. N., Rabinovitch, B., Macklem, P. T., and Pardy, R. L. (1985). Effects of separate rib cage and abdominal restriction on exercise performance in normal humans. J. Appl. Physiol. 58, 2020-2026.

Jones, N. L., Makrides, L., Hitchcock, C., Chypchar, T., and McCartney, N. (1985). Normal standards for an incremental progressive cycle ergometer test. Am. Rev. Respir. Dis. 131, 700-708.

Kabitz, H. J., Lang, F., Walterspacher, S., Sorichter, S., Muller-Quernheim, J. and Windisch, W. (2006). Impact of impaired inspiratory muscle strength on dyspnea and walking capacity in sarcoidosis. Chest 130, 1496-1502. doi: $10.1378 /$ chest.130.5.1496

Kabitz, H. J., Walterspacher, S., Walker, D., and Windisch, W. (2007). Inspiratory muscle strength in chronic obstructive pulmonary disease depending on disease severity. Clin. Sci. 113, 243-249. doi: 10.1042/CS20060362

Koo, P., Gartman, E. J., Sethi, J. M., and McCool, F. D. (2015). Physiology in Medicine: physiological basis of diaphragmatic dysfunction with abdominal hernias-implications for therapy. J. Appl. Physiol. 118, 142-147. doi: 10.1152/japplphysiol.00276.2014

Koulouris, N., Mulvey, D. A., Laroche, C. M., Goldstone, J., Moxham, J., and Green, M. (1989). The effect of posture and abdominal binding on respiratory pressures. Eur. Respir. J. 2, 961-965.

Laghi, F., and Tobin, M. J. (2003). Disorders of the respiratory muscles. Am. J. Respir. Crit. Care Med. 168, 10-48. doi: 10.1164/rccm.2206020

Laghi, F., Jubran, A., Topeli, A., Fahey, P. J., Garrity, E. R. Jr., Arcidi, J. M., et al. (1998). Effect of lung volume reduction surgery on neuromechanical coupling of the diaphragm. Am. J. Respir. Crit. Care Med. 157, 475-483. doi: $10.1164 /$ ajrccm.157.2.9705082

Martin-Valero, R., Zamora-Pascual, N., and Armenta-Peinado, J. A. (2014), Training of respiratory muscles in patients with multiple sclerosis: a systematic review. Respir. Care 59, 1764-1772. doi: 10.4187/respcare. 02881

McCool, F. D., Pichurko, B. M., Slutsky, A. S., Sarkarati, M., Rossier, A., and Brown, R. (1986). Changes in lung volume and rib cage configuration with abdominal binding in quadriplegia. J. Appl. Physiol. 60, 1198-1202.

Mendonca, C. T., Schaeffer, M. R., Riley, P., and Jensen, D. (2014). Physiological mechanisms of dyspnea during exercise with external thoracic restriction: 
role of increased neural respiratory drive. J. Appl. Physiol. 116, 570-581. doi: 10.1152/japplphysiol.00950.2013

Meyer, F. J., Borst, M. M., Zugck, C., Kirschke, A., Schellberg, D., Kubler, W., et al. (2001). Respiratory muscle dysfunction in congestive heart failure: clinical correlation and prognostic significance. Circulation 103, 2153-2158. doi: 10.1161/01.CIR.103.17.2153

Miller, J. D., Beck, K. C., Joyner, M. J., Brice, A. G., and Johnson, B. D. (2002). Cardiorespiratory effects of inelastic chest wall restriction. J. Appl. Physiol. 92, 2419-2428. doi: 10.1152/japplphysiol.00394.2001

Miller, M. R., Hankinson, J., Brusasco, V., Burgos, F., Casaburi, R., Coates, A., et al. (2005). Standardisation of spirometry. Eur. Respir. J. 26, 319-338. doi: 10.1183/09031936.05.00034805

Moodie, L., Reeve, J., and Elkins, M. (2011). Inspiratory muscle training increases inspiratory muscle strength in patients weaning from mechanical ventilation: a systematic review. J. Physiother. 57, 213-221. doi: 10.1016/S1836-9553(11)70051-0

Nishimura, Y., Maeda, H., Tanaka, K., Nakamura, H., Hashimoto, Y., and Yokoyama, M. (1994). Respiratory muscle strength and hemodynamics in chronic heart failure. Chest 105, 355-359. doi: 10.1378/chest.105.2.355

O'Donnell, D. E., Hong, H. H., and Webb, K. A. (2000). Respiratory sensation during chest wall restriction and dead space loading in exercising men. J. Appl. Physiol. 88, 1859-1869.

Parshall, M. B., Schwartzstein, R. M., Adams, L., Banzett, R. B., Manning, H. L., Bourbeau, J., et al. (2012). An official American Thoracic Society statement: update on the mechanisms, assessment, and management of dyspnea. Am. J. Respir. Crit. Care Med. 185, 435-452. doi: 10.1164/rccm.201111-2042ST

Petrof, B. J., Jaber, S., and Matecki, S. (2010). Ventilator-induced diaphragmatic dysfunction. Curr. Opin. Crit. Care 16, 19-25. doi: 10.1097/MCC.0b013e328334b166

Polkey, M. I., Kyroussis, D., Hamnegard, C. H., Mills, G. H., Green, M., and Moxham, J. (1996). Diaphragm strength in chronic obstructive pulmonary disease. Am. J. Respir. Crit. Care Med. 154, 1310-1317. doi: $10.1164 /$ ajrccm.154.5.8912741

Richard, R., Lonsdorfer-Wolf, E., Charloux, A., Doutreleau, S., Buchheit, M., Oswald-Mammosser, M., et al. (2001). Non-invasive cardiac output evaluation during a maximal progressive exercise test, using a new impedance cardiograph device. Eur. J. Appl. Physiol. 85, 202-207. doi: 10.1007/s004210 100458

Schaeffer, M. R., Mendonca, C. T., Levangie, M. C., Andersen, R. E., Taivassalo, T., and Jensen, D. (2014). Physiological mechanisms of sex differences in exertional dyspnoea: role of neural respiratory motor drive. Exp. Physiol. 99, 427-441. doi: 10.1113/expphysiol.2013.074880

Smart, N. A., Giallauria, F., and Dieberg, G. (2013). Efficacy of inspiratory muscle training in chronic heart failure patients: a systematic review and meta-analysis. Int. J. Cardiol. 167, 1502-1507. doi: 10.1016/j.ijcard.2012.04.029

Stubbing, D. G., Pengelly, L. D., Morse, J. L., and Jones, N. L. (1980). Pulmonary mechanics during exercise in normal males. J. Appl. Physiol. 49, 506-510.

Tan, W. C., Bourbeau, J., Hernandez, P., Chapman, K., Cowie, R., FitzGerald, M. J., et al. (2011). Canadian prediction equations of spirometric lung function for
Caucasian adults 20 to 90 years of age: results from the Canadian Obstructive Lung Disease (COLD) study and the Lung Health Canadian Environment (LHCE) study. Can. Respir. J. 18, 321-326. doi: 10.1155/2011/540396

Tantucci, C., Massucci, M., Piperno, R., Betti, L., Grassi, V., and Sorbini, C. A. (1994). Control of breathing and respiratory muscle strength in patients with multiple sclerosis. Chest 105, 1163-1170. doi: 10.1378/chest.105.4.1163

Uva, B., Aliverti, A., Bovio, D., and Kayser, B. (2015). The "Abdominal Circulatory Pump": an auxiliary heart during exercise? Front. Physiol. 6:411. doi: 10.3389/fphys.2015.00411

van Hees, H. W., Dekhuijzen, P. N., and Heunks, L. M. (2009). Levosimendan enhances force generation of diaphragm muscle from patients with chronic obstructive pulmonary disease. Am. J. Respir. Crit. Care Med. 179, 41-47. doi: 10.1164/rccm.200805-732OC

Vanmeenen, M. T., Ghesquiere, J., and Demedts, M. (1984). Effects of thoracic or abdominal strapping on exercise performance. Bull. Eur. Physiopathol. Respir. $20,127-132$

Vivier, E., Metton, O., Piriou, V., Lhuillier, F., Cottet-Emard, J. M., Branche, P., et al. (2006). Effects of increased intra-abdominal pressure on central circulation. Br. J. Anaesth. 96, 701-707. doi: 10.1093/bja/ael071

West, C. R., Campbell, I. G., Goosey-Tolfrey, V. L., Mason, B. S., and Romer, L. M. (2014a). Effects of abdominal binding on field-based exercise responses in Paralympic athletes with cervical spinal cord injury. J. Sci. Med. Sport 17, 351-355. doi: 10.1016/j.jsams.2013.06.001

West, C. R., Campbell, I. G., Shave, R. E., and Romer, L. M. (2012a). Effects of abdominal binding on cardiorespiratory function in cervical spinal cord injury. Respir. Physiol. Neurobiol. 180, 275-282. doi: 10.1016/j.resp.2011.12.003

West, C. R., Campbell, I. G., Shave, R. E., and Romer, L. M. (2012b). Resting cardiopulmonary function in Paralympic athletes with cervical spinal cord injury. Med. Sci. Sports Exerc. 44, 323-329. doi: 10.1249/MSS.0b013e31822b7441

West, C. R., Goosey-Tolfrey, V. L., Campbell, I. G., and Romer, L. M. (2014b). Effect of abdominal binding on respiratory mechanics during exercise in athletes with cervical spinal cord injury. J. Appl. Physiol. 117, 36-45. doi: 10.1152/japplphysiol.00218.2014

Wilson, T. A., and De Troyer, A. (2013). Effects of the insertional and appositional forces of the canine diaphragm on the lower ribs. J. Physiol. 591, 3539-3548. doi: 10.1113/jphysiol.2013.253286

Conflict of Interest Statement: The authors declare that the research was conducted in the absence of any commercial or financial relationships that could be construed as a potential conflict of interest.

Copyright $\odot 2017$ Abdallah, Chan, Glicksman, Mendonca, Luo, Bourbeau, Smith and Jensen. This is an open-access article distributed under the terms of the Creative Commons Attribution License (CC BY). The use, distribution or reproduction in other forums is permitted, provided the original author(s) or licensor are credited and that the original publication in this journal is cited, in accordance with accepted academic practice. No use, distribution or reproduction is permitted which does not comply with these terms. 